\title{
TEORI PERKEMBANGAN MORAL DAN MODEL PENDIDIKAN MORAL
}

\author{
Agus Abdul Rahman \\ Fakultas Psikologi UIN Sunan Gunung Djati Bandung \\ J1. Raya Cipadung No. 105 Bandung 10614 Telp (022) 7800525 email:a_abdurrahman72@yahoo.com
}

\begin{abstract}
Moral values and it's decadence were one of many problems that in Indonesia, whereas becoming a huge responsibility that hold by all member of society. The inquiry, designing and implementation of moral education strategy is foreseen as the most important aspect to improve society. Aside from great efforts to improve society, it is imperative that we also need to review and inquire more about moral development theory. Nowadays, it seems that moral development theory had moved from its role and position which moved from its autonomic, rationalistic and universalistic nature to more emotionally roles and becoming more culture bounded. The changes in society paradigm were also have many implications on education of moral development. In this paper there are at least 3 models that can be used in moral education, which are the learning of rule ethics, character ethics and the integration of both in multidimensional fields.
\end{abstract}

Keywords : rules ethics, character ethic, integrative approach

\section{Pendahuluan}

Krisis multidimensional yang selama ini disebut-sebut sedang menimpa bangsa kita tampaknya bukan hanya isapan jempol semata. Rentetan peristiwa yang tersaji di media-media sepertinya mempertegas bahwa bangsa ini memang sedang krisis. Yang lebih mengkhawatirkan lagi, krisis tersebut juga terjadi pada dunia pendidikan kita. Kasus-kasus mutakhir yang terekspos di media seperti pelecehan seksual dan kekerasan guru terhadap siswa, bulliying siswa terhadap siswa lainnya, penggunaan narkoba, seks bebas, ataupun aborsi di kalangan siswa adalah sebagian potret buram mengenai wajah dunia pendidikan kita. Sebagai gambaran, survei yang dilakukan Badan Narkotika Nasional dan Universitas Indonesia terhadap 73.842 pelajar dan mahasiswa di 33 provinsi di Indonesia menunjukkan bahwa sebanyak 1.037 .682 pelajar dan mahasiswa di Indonesia diketahui telah mengkonsumsi narkotik dan obat-obatan terlarang lainnya (narkoba). Angka itu merupakan 32 persen dari total 3,2 juta pengguna narkoba secara nasional (Koran Tempo, 11 September 2007). Survey mutakhir terhadap pelajar SMP dan SMA di 33 propinsi yang dilakukan komisi perlindungan anak menunjukkan bahwa 62,7 persennya sudah tidak perawan lagi (Pikiran rakyat, 11 Desember 2008).

Kenyataan tersebut tentu membuat kaget banyak kalangan. Pendidikan yang semestinya mempunyai fungsi sosialisasi nilai-nilai, pengembangan diri, dan kontrol sosial tampaknya justru menghasilkan sesuatu yang agak paradoks. Lalu apa yang harus dilakukan?

Dewasa ini pendidikan formal memang menghadapi tantangan yang sangat luar biasa. Sementara masalah-masalah internal (tata pamong, kurikulum, sarana dan prasarana, keuangan, sumber daya manusia) masih belum 
terselesaikan dengan baik, sekolah harus berhadapan dengan arus globalisasi yang memiliki dampak yang sangat luas terhadap setiap segmen kehidupan. Struktur, norma, gaya hidup, dan karakteristik masyarakat yang berubah dengan cepat menuntut sekolah untuk terus-menerus mengevaluasi serta mereformasi dirinya.

Namun demikian, seberat apapun tantangannya sekolah harus tetap menjalankan fungsinya. Sekolah harus berusaha semaksimal mungkin mensosialisasikan nilai-nilai dan membentuk karakter siswa yang sesuai dengan nilai-nilai tersebut. Sekolah tidak boleh puas dengan hanya memperkaya kemampuan kognitif siswa saja, sementara perilaku moral siswa diabaikan.

\section{Pembahasan}

Pendidikan moral bukanlah perkara sepele atau main-main. Telah terjadi diskusi panjang tentang bagaimana pendidikan moral dilakukan sehingga nilai-nilai dapat terinternalisasi dengan baik dan muncul perilaku moral yang sesuai dengan nilai-nilai tersebut. Banyak teori bermunculan tentang perkembangan moral dan pendidikan moral. Dari mulai Jean piaget, Lawrence kolhberg, Marvin W. Ber-kowitz, Thomas Lichona, Elliot Turiel, Larry P. Nucci, Jonathan Haidt, sampai Darcia Narvaez telah banyak melahirkan teori tentang perkembangan moral dan pendidikan moral.

\section{Teori Perkembangan Moral}

Jean Piaget bisa dibilang sebagai orang yang pertama kali meneliti perkembangan moral (Lapsley, 2006). Piaget meneliti moral judgment pada anak, dan menulis buku berjudul "The Moral Judgment of The Child" pada tahun 1932. Penelitian Piaget kemudian dikembangkan oleh Lawrence Kohlberg pada tahun 1970-an. Teori Kohlberg mengenai Moral Reasoning atau Cognitive Model of Moral Development mendapatkan banyak perhatian dan memberikan pengaruh pada penelitian-penelitian mengenai perkembangan moral.

Namun demikian, teori Kohlberg tidak lepas dari kritik. Carol Gilligan, seorang feminis misalnya, menyampaikan kritik pada artikelnya yang cukup berpengaruh di Harvard Educational Review pada tahun 1997 dan buku best-sellernya In a Different Voice pada tahun 1982. Gilligan mengklaim bahwa moralitas perempuan secara kualitatif berbeda dibanding moralitas laki-laki. Menurutnya, prinsip moral reasoning perempuan adalah ethic of care, sedangkan laki-laki adalah ethic of justice (Walker, 2006). Gilligan mengkritik bahwa Kohlberg hanya membatasi diri pada pada prinsip keadilan (ethic of justice), dan bersifat diskriminatif karena tidak mempertimbangkan perbedaan gender.

Kritik lain disampaikan oleh Eliot Turiel dengan social cognitive domain theory. Dalam beberapa hal, antara Kohlberg (structuraldevelopment theory) dan Turiel (socialcognitive domain perspectives) sebenarnya memiliki beberapa kesamaan. Keduannya menyampaikan bahwa perkembangan moral akan lebih baik dipahami dengan menganalisa moral judgment. Emosi dianggap terpisah dan tidak memotivasi kekuatan moral judgment, se- 
dangkan perilaku dianggap hasil dari moral judgment. Keduanya juga menganggap bahwa moralitas terbentuk bukan karena interaksi individu dan lingkungannya. Kritik Turiel terhadap Kohlberg adalah bahwa moralitas hanyalah satu dari tiga bentuk pengetahuan sosial (Social Knowledge). Pengetahuan sosial, menurut Turiel, ditandai dengan heterogeneity dan coexistence antara orientasi sosial, motivasi dan tujuan. Jadi, pemahaman mengenai justice, welfare, dan right (moral issues) coexist dengan authority, tradition, social norms (social conventional issues), dan privacy, bodily integrity and control, dan delimited set of choices and preferences (personal issues) (Smetana, 2006). Turiel (2006) mengatakan bahwa untuk memahami fungsi dan perkembangan moral yang ada pada suatu masyarakat ada baiknya memahami juga kultur dan struktur masyarakatnya. Menurut Turiel, (2006) :

"In some cultural analyses, inequalities are seen as acceptable to members of the group because of asymmetrical reciprocity; that is, the subordinate accepts his or her status and is compensated by the advantages of the care given by those in dominant positions, and because of an upbringing that shapes the individual to participate in a collective system of interdependence and duties"

Masyarakat seperti itu jika dinilai dengan menggunakan standard yang berbeda, misal ethic of justice, tentu, akan menimbulkan kritik dan kesalahan. Namun demikian, Turiel masih menganggap bahwa teorinya bersifat universal.
Kritik berikutnya muncul dari kalangan cultural psychology dan cross-cultural psychology. Kritik terutama terhadap klaim bahwa terdapat prinsip-prinsip moral yang bersifat universal, seperti yang disampaikan oleh Jean Piaget, Lawrence Kohlberg, Gilligan, ataupun Elliot Turiel. Cultural psychology memegang premis bahwa proses kultural dan proses psikologis sama-sama penting di dalam memahami perkembangan moral (Miler, 2007). Cultural psychology berpendapat bahwa domain moral secara kultural beragam dan lebih luas daripada sekedar domain yang berhubungan dengan harm, right, dan justice (Haidt, dkk., 1993). Cultural psychology juga mengakui adanya non-rasionalitas di dalam konsepsi moral. Berbeda dengan mainstream teori psikologi tentang moral yang mengabaikan peran agama dalam pembentukan moralitas, cultural psychology justru mengakuinya Shweder, dkk (1997), misalnya, berdasarkan penelitian ethnografis di India, Brazil, dan Amerika, mengidentifikasi tiga moral domain yang salah satunya moralitas yang berhubungan dengan agama, yaitu autonomy, community, dan divinity. Penelitian Shweder menunjukkan bahwa ethic of autonomy saja tidak cukup untuk menjelaskan perilaku moral dalam berbagai kultur. Pada kultur-kultur lain, perilaku moral juga ditentukan oleh ethic of community, dan ethic of divinity. Artinya, menurut Shweder bahwa perilaku moral seseorang juga dipengaruhi oleh pertimbangan-pertimbangan kelompok bahkan tuhan, jadi tidak hanya ditentukan oleh moral reasoning semata. 
Kritik yang lain disampaikan oleh Jonathan Haidt. Hampir sama dengan Shweder, dkk., Haidt mengkritik main-streams psikologi moral yang lebih menekankan pada rasionalitas, otonomi, dan penekanan berlebih pada prinsip harm, right, dan justice. Menurut Haidt, dkk. (1993), walaupun Turiel ataupun Killen dan Helwig sudah menyatakan bahwa aturan moral tertentu boleh jadi berbeda dari satu kultur dengan kultur yang lainnya, tapi mereka masih menganggap bahwa prinsip moral di seluruh budaya tidak terlepas dari harm, rights, atau justice. Bagi Haidt (2001), moral reasoning bukanlah yang menyebabkan moral judgement. Moral reasoning seringkali bersifat post hoc construction, yaitu dibuat setelah moral judgment dilakukan. Sebagai alternatif, Haidt (2001) kemudian menekankan pentingnya pengaruh faktor sosial dan kultural terhadap moral judgment. Baginya, moral judgment secara umum merupakan hasil dari evaluasi yang sifatnya cepat atau otomatis atau bersifat intuitif (intuition) daripada rasional.

Lebih lanjut, Haidt (2009) menjelaskan bahwa moral intuition merupakan mekanisme psikologis yang sifatnya innate, tapi juga dipengaruhi oleh institusi dan praktek-praktek kultural. Karena bisa dipengaruhi, maka orang tua atau agent sosialisasi moral yang lainnya bisa membangun moral foundation tertentu pada anak. Berdasarkan surveynya terhadap list of virtue dari berbagai kultur, Haidt (2007) mendapatkan 5 moral foundation. Kelima moral foundation tersebut adalah Harm/care, Fairness/reciprocity, Ingroup/loyalty, Authority/ respect, dan Purity/sanctity.
Yang menarik adalah apa yang disampaikan oleh Shweder, dkk tentang ethic of divinity dan Haidt dkk. tentang ethic of purity. Walaupun istilahnya berbeda, kedua ethic tersebut sebenarnya menunjuk pada substansi yang sama (Horberg E.J, Oveis C, Keltner D, Cohen AB, 2009; Haidt, 2009). Keduanya mengakui adanya pengaruh sesuatu yang dimahakan terhadap moral judgment dan adanya prinsip-prinsip moral yang sifatnya private dan spirituil. Domain of Purity, menurut Horberg, dkk (2009), meliputi nilai-nilai dan prinsip-prinsip yang bertujuan untuk menjaga kesucian tubuh dan jiwa. Lebih lanjut, Horberg, dkk. (2009) menambahkan bahwa domain of purity juga meliputi "the belief that people ought to be, in their bodies and minds, clean, chaste, selfrestrained, and spiritually pure and should strive to live in a sacred, divine way (which does not necessarily require belief in deity)".

Dalam formulasi Shweder, pelanggaran terhadap ethic of care and justice dan ethic of purity akan menimbulkan reaksi yang berbeda. Pelanggaran terhadap ethic of care and justice akan menimbulkan ketidakberhargaan atau disrespect, sedangkan pelanggaran terhadap ethic of purity akan menimbulkan perasaan tidak suci, rasa bersalah, kejijikan atau disgust (Haidt J, Roller SH, Dias MG, 1993). Menurut Haidts, dkk. (1993), Disgust mungkin merupakan komponen moralitas yang sifatnya umum. Dalam berbagai kultur, termasuk dalam masyarakat global sekalipun, terdapat perilakuperilaku yang jika dilakukan akan menimbulkan disgust. Looy (2004) menggambarkan 
bahwa disgust berakar dalam tubuh. Menurutnya, disgust merupakan "moral emotion yang fungsi khususnya adalah memfasilitasi evaluasi baik dan buruk, benar atau salah, dan sekaligus menyatakan keterikatan (embeddedness)". Masih menurut Looy, pemicu munculnya Disgust banyak berhubungan dengan tuntutan dan harapan sesuatu yang dimahakan dan merefleksikan sisi spiritualitas manusia. Terakhir, Disgust ini penting karena bisa merupakan "as gurdian of the temple of the body" (Haidt, Rozin, McCauley, dan Imada, 1997) dan dapat melindungi kesucian tubuh dan jiwa (Horbeg, Oveis C, Keltner, dan Cohen, 2009).

Jadi, perkembangan teori mengenai perkembangan moral sudah banyak mengalami pergeseran. Teori moral reasoning dan moral judgment dari Piaget dan Kohlberg yang cukup lama mendomi-nasi penelitian psikologi moral dan mem-pengaruhi pendidikan moral sudah banyak mendapatkan koreksi. Penekanan berlebih terhadap peran rasio dalam penilaian moral, prinsip keadilan, dan universalitas teori sudah mengalami pergeseran ke arah yang lebih menghargai peran penting emosi di dalam penilaian moral, prinsip-prinsip moral menjadi lebih beragam dan berkait dengan budah, culture-bound. Pergeseran ini dapat dipahami karena akhir-akhir ini tengah berkembang pesat penelitian-penelitian mengenai social neuroscience (pengaruh fungsi neural terhadap perilaku sosial) dan munculnya perhatian yang sangat intens terhadap budaya dan pengaruhnya terhadap perilaku sosial.

\section{Model Pendidikan Moral}

Perkembangan teori mengenai perkembangan moral yang sudah dijelaskan ternyata berpengaruh besar pada bagaimana nilai-nilai moral diajarkan di sekolah-sekolah. Menurut Narvaez (2008), terdapat dua pendekatan dalam pendidikan moral. Pertama, pendekatan yang bersifat universalis - Narvaez menyebutnya dengan rule ethics. Pendekatan ini menekankan pada apa yang sebaiknya dilakukan pada situasi moral tertentu. Pendekatan ini banyak dipengaruhi oleh teori moral judgmen dan moral reasoning dari Jean Piaget dan Lawrence Kohlberg. Perilaku moral, menurut pendekatan ini, sangat ditentukan oleh kemampuan moral reasoning seseorang. Karena pentingnya moral reasoning, maka pendidikan moral lebih diarahkan pada peningkatan kemampuan moral reasoning berdasarkan prinsip justice dan fairness, seperti belajar memecahkan dilema-dilema moral yang seringkali dihadapi siswa dalam kehidupan sehari-hari.

Pendekatan ini lebih mengedepankan proses daripada isi dan menganggap faktor lingkungan bukan merupakan faktor penting di dalam membentuk moral reasoning siswa. Pendekatan ini kadang dianggap menggunakan pendekatan tidak langsung terhadap perkembangan moral (Narvaez, 2006). Sebab, siswa tidak diarahkan secara langsung untuk meyakini atau melakukan suatu perilaku moral. Peran guru atau orang dewasa pada pendekatan ini lebih sebagai fasilitator. Guru atau orang dewasa bertugas menguji perspektif siswa, membangun empati, mendo-rong dis- 
kusi, memperkaya perspektif dan kemampuan berfikir siswa, serta membantu siswa belajar membuat keputusan yang baik.

Walaupun demikian, perkembangan berikutnya, Kohlberg dengan Just Community Schoolnya kemundian menambahkan pentingnya iklim sekolah di dalam meningkatkan moral reasoning siswa. Menurutnya, adalah penting siswa memahami dan merasakan keadilan di sekolah dengan mendapatkan perlakuan yang adil.

Pendekatan kedua adalah pendekatan yang sifatnya partikularis (character ethics). Pendekatan ini mengutamakan penguasaan nilai-nilai keutamaan atau virtue yang dianggapnya perlu dan memadai untuk mendapatkan kehidupan yang baik. Model pendidikan moral dengan pendekatan ini sebenarnya secara tradisional sudah lama diterapkan. Tapi, karena besarnya pengaruh teori moral reasoning dari Piaget dan Kohlberg dan faktorfaktor lainnya, model pendidikan character ethic kemudian mengalami kemunduran. Model pendidikan character ethic mendapat perhatian kembali setelah teori moral reasoning mendapatkan banyak kritik dan munculnya penjelasan menyakinkan mengenai perlunya emosi di dalam pembentukan perilaku moral.

Fokus pendidikan moral dengan pendekatan ini lebih pada bagaimana membentuk karakter. Selain karena karakter tersebut tidak dibawa sejak lahir juga diyakini bahwa perilaku moral seseorang akan konsisten dengan karakter yang dimilikinya. Pendekatan ini, terutama yang tradisional, lebih mene- kankan pada tradisi, otoritas, dan kepatuhan daripada penalaran, otonomi, ataupun keadilan sosial (Narvaez, 2006). Selain itu, pendekatan ini lebih bersifat a teacher-centered dan direct teaching approach (Benninga, 1991; Solomon, dkk., 2002). Dalam prakteknya, siswa memang dituntut untuk meyakini dan melakukan suatu perilaku moral tanpa terlalu perduli apakah siswa memahami dan merasakan keadilan ataupun tidak. Menurut Narvaez (2006), terdapat dua penekanan pada pendekatan ini. Pertama, pendekatan ini lebih mengutamakan isi daripada proses, dan yang kedua pendekatan ini menganggap penting lingkungan di dalam membentuk perilaku moral.

Sebenarnya, seperti yang disampaikan Narvaez (2008), selain kedua model pendidikan moral seperti yang sudah disampaikan, terdapat model pendidikan moral yang lain yang sifatnya integratif atau multidimentional. Model ini berusaha menggabungkan rule ethic dan character ethic dan yang termasuk tokoh integrative model tersebut antara lain Thomas Lichona, Darcia Narvaez dan Marvin W. Berkowitz.

Menurut Lichona, karakter moral bersifat multidimensional. Menurut Lichona, pendidikan moral bertujuan untuk membangun kualitas karakter yang positif atau virtue. Baginya, karakter moral terdapat tiga komponen, yaitu moral knowledge, moral feeling, dan moral behavior. Artinya, perilaku moral saja bagi Lichona tidaklah cukup, perilaku moral tersebut harus dibarengi dengan pengetahuan dan perasaan tentang apakah 
perilaku tersebut termasuk perilaku moral atau bukan.

\section{Simpulan}

Lickona (dalam Narvaez, 2006) menggambarkan 12 strategi komprehensif pendidikan karakter :

1. Guru merupakan caregiver, moral model, dan moral mentor ketika berhubungan dengan siswa. Guru memperlakukan siswa dengan penuh penghargaan

2. Guru menciptakan komunitas kelas yang saling perduli dengan menciptakan komunitas peer group yang positif

3. Guru mengajarkan disiplin moral. Disiplin merupakan alat untuk pengembangan karakter, digunakan untuk mengembangkan respect, reasoning dan self control

4. Guru menciptakan komunitas yang demokratis yaitu siswa terlibat dalam pengambilan-pengambilan keputusan

5. Guru memelihara nilai-nilai melalui kurikulum

6. Guru menggunakan cooperative learning untuk membantu siswa belajar menyatu dengan yang lainnya dan memiliki sense of community

7. Guru mengembangkan conscience of craft dengan menggabungkan antara harapan tinggi dan dukungan yang tinggi

8. Guru menggunakan refleksi etis di dalam membantu siswa merefleksikan perspektif orang lain, mempertimbangkan persyaratan kongkrit dari suatu virtue

9. Guru membantu siswa untuk memecahkan konflik dengan damai dengan menggunakan ketrampilan memecahkan konflik

10. Sekolah menciptakan kultur moral positif

11. Sekolah memberikan kesempatan pada siswa untuk menunjukan keperdulian pada masyarakat

12. Sekolah merekrut orang tua dan masyarakat sebagai rekanan di dalam upaya melakukan pendidikan karakter

Berkowitz terkenal dengan teori moral anatomynya. Berkowitz berusaha mengintegrasikan antara identitas moral, kepribadian, dan model pendidikan karakter. Moral anatomy Berkowitz terdiri dari tujuh komponen, yaitu moral behavior, moral character (kecenderungan yang terinternalisasi untuk melakukan suatu perilaku yang benar), moral values, moral reasoning, moral emotion, moral identity, dan metamoral characteristic seperti disiplin diri. Terakhir, Narvaez terkenal dengan Integrative Ethical Education. Model integrative moral education dari Narvaez terdiri dari tiga ide dasar. Pertama, bahwa pengembangan moral berarti pengembangan moral expertise. Implikasinya adalah guru harus mengajarkan proses dan keterampilan perilaku moral dan guru harus mengajarkan baik moral virtue atau-pun moral reasoning. Kedua, pendidikan moral bersifat transformatif dan interaktif. Implikasinya, guru harus mensetting struktur lingkungan dengan baik sehingga dapat meningkatkan moral intuition dan guru harus merancang instruksi yang dapat mendorong siswa menjadi lebih kompeten dalam ethical know-how. Ketiga, karakteristik 
alamiah manusia besifat kooperatif dan aktualisasi diri. Implikasinya, guru harus membantu menciptakan komunitas baik di dalam maupun di luar sekolah dan guru harus meningkatkan kemampuan regulasi diri siswa dan komunitas. (lihat Narvaez, 2008).

\section{Daftar Pustaka}

Haidt, J. (2001). The Emotional Dog and Its Rational Tail: A Social Intuitionist Approach to Moral Judgment.

Psychological Review, 2001. Vol. 108. No. 4, 814-834

Haidt, J., \& Graham, J. (2007). When morality opposes justice: Con-servatives have moral intuitions that liberals may not recognize. Social Justice Research, 20, 98-116.

Haidt, Roller, dan Dias (1993). Affect, Culture, and Morality, or Is It Wrong to Eat \bur Dog? Journal of Personality and Social Psychology, 1993, Vol. 65, No. 4, 613628

Haidt, J., Graham, J., \& Nosek, B.A. (2009). Liberals and Conservatives Rely on Different Sets of Moral Foundations. Journal of Personality and Social Psychology, 2009, Vol. 96, No. 5, 10291046

Haidt, J., P. Rozin, C. McCauley, and S. Imada. 1997. "Body, Psyche, and Culture: The Relationship between Disgust and Morality." Psychology and Developing Societies 9:107-31.

Halstead, J.M. (2007) Islamic values: a distinctive framework for moral education? Journal of Moral Education Vol. 36, No. 3, September 2007, pp. 283-296

Lapsley, D.K. (2006). Moral Stage Theory. In Klillen, M. and Smetana, J.G. (Ed.). Hanbook of Moral Development. New Jersey London. Lawrence Erlbaum Associates, Publishers

Miller, J.G. (2007). Cultural Psychology of Moral Development. In Kitayama, S. \& Cohen, D. (Ed.). Handbook of Cultural Psychology. New York. London. The Guilford Press
Narvaez, D. (2008). Human Flourishing and Moral Development: Cognitive and Neurobiological Perspectives of Virtue Development. In Nucci Larry P, Narvaez Darcia (Editor). 2008. Handbook of moral and character education. Taylor $\&$ Francis

Narvaez, D. (2006). Integrative Ethical Education. In Klillen, M. and Smetana, J.G. (Ed.). Hanbook of Moral Development. New Jersey London. Lawrence Erlbaum Associates, Publishers

Seligman, M. (2002). Authentic Happiness: Using the new positive psychology to realize your potential for lasting fulfillment. New York: Free Press

Smetana, J.G (2006). Social-Cognitive Domain Theory : Consistencies and Variations in Children's Moral and Social Judgments. In Klillen, M. and Smetana, J.G. (Ed.). Hanbook of Moral Development. New Jersey London. Lawrence Erlbaum Associates, Publishers.

Turiel, E. (2008). Thought about actions in social domains: Morality, social conventions, and social interactions. Cognitive Development (2008) 136154

Turiel, E. (2006). Thought, Emotions, and Social Interactional Processes in Moral Development. In Klillen, M. and Smetana, J.G. (Ed.). Hanbook of Moral Development. New Jersey London. Lawrence Erlbaum Associates, Publishers.

Peterson, Christopher dan Seligman M.E.P, 2004. Character strengths and virtues: a handbook and classification. American Psycho-logical Association 750 First Street, NE, Washington, DC 20002-4242

Walker, L.J. (2006). Gender and Morality. In Klillen, M. and Smetana, J.G. (Ed.). Handbook of Moral Development. New Jersey London. Lawrence Erlbaum Associates, Publishers. 